\title{
I want YOU! \\ An experiment studying the selection effect when assigning distributive power
}

\author{
By \\ Jordi Brandts*, Werner Güth** and Andreas Stiehler***
}

May 15, 2002

\begin{abstract}
$\underline{\text { Abstract }}$
We study whether selection affects motivation. In our experiment subjects first answer a personality questionnaire. They then play a 3-person game. One of the three players decides between an outside option assigning him a positive amount, but leaving the two others empty-handed and allowing one of the other two players to distribute a pie. Treatments differ in the procedure by which distributive power is assigned: to a randomly determined or to a knowingly selected partner. Before making her decision the selecting player could consult the personality questionnaire of the other two players. Results show that knowingly selected players keep less for themselves than randomly selected ones and reward the selecting player more generously.
\end{abstract}

*Institut d'Anàlisi Econòmica (CSIC), Barcelona.

** Max Planck Institut, Jena.

*** Humboldt-Universität zu Berlin.

The authors thank the participants of the ESA-Meeting (Barcelona, 2001), the IAREP-Conference (Bath, 2001), the ENDEAR-Workshop (Amsterdam, 2001) and of the "GEW-Jahrestagung" (Magdeburg, 2001) and especially Martin Dufwenberg for their very helpful comments. Financial support by the European Union through the TMR research network ENDEAR (FMRX-CT98-0238) is gratefully acknowledged. 


\section{INTRODUCTION AND MOTIVATION.}

In many economic and social situations people assign power over the distribution of payoffs to others. This is because we live in a world in which contracts are incomplete and thus leave considerable discretion. Examples from economic life are labor markets with hidden effort and goods markets with variable quality. In this kind of markets it is not possible to completely specify the features of the goods or services to be transacted. As a consequence, having been hired may give a worker considerable power over the distribution of payoffs between herself and the employer. In a similar manner the purchase of a good or service of uncontractable quality allows the seller to take advantage of her customers. The problem is also present within organizations and firms; the assignment of certain tasks to particular employees often entails giving them some kind of allocative power.

In this kind of environments, issues related to cooperative behavior can play a prominent role. We know from previous experiments that, in different variants of sequential relations, gift exchange is a reliable behavioral phenomenon. Those who act first frequently make - at own cost - choices that favor those who act second who then take - again at own cost - actions that favor the first movers.

In the investment game (Berg, Dickhaut and McCabe, 1995) a truster can assign dictatorial power to a trustee in a continuous way. Let $\mathrm{k}$ be the positive monetary endowment of the truster and $\mathrm{m}$ a multiplier with $\mathrm{m} \geq 1$. For any investment $\mathrm{x}$ by the truster, with $0 \leq \mathrm{x} \leq \mathrm{k}$, the trustee receives $\mathrm{mx}$ of which she can send any share $\mathrm{y}$, with $0 \leq \mathrm{y} \leq \mathrm{mx}$, back to the truster. The data from experiments with this game exhibit both considerable investment and pay-back. Fehr, Kirchsteiger and Riedl (1993) present the gift exchange game and find similar results. 
The above studies focus on whether the dictator's choices are affected by the procedure by which she has been selected. A relevant behavioral issue may, hence, have been left aside. In many instances individuals obtain discretionary power over others after having been selected among a pool of candidates. A selection procedure is usually considered to have an allocative impact; a good procedure will presumably select the candidate with the most appropriate characteristics. The procedure may, however, also cause other effects, e.g. the selected party may express gratitude to other parties involved. When selecting an employee, employers usually select one person from a pool of several candidates. Moreover, employers most often gather considerable information about the characteristics of the candidates and decide on that basis. The person that gets the job usually knows that the employer has used information about her. If that very fact subsequently affected the employee's behavior then there would be a purely psychological reason for following personalized selection processes. This possibility is the focus of our study.

Issues related to the effects of job selection processes have been studied by a number of investigators in non-experimental contexts. Hough and Oswald (2000) present an overview of current research on personnel selection. Gilliland (1993, p. 727) concludes that evaluations of the fairness of the selection process "will have an impact on the work behavior of a person who is hired, which is exhibited through work performance, organizational citizenship behaviors, his or her attitudes such as job satisfaction and organizational commitment, and the organizational climate". Some studies deal directly with applicants' reactions to positive selection outcomes. Bauer, Maertz, Dolen and Campion (1998) find that applicants passing a test for a clerical position rated organizational attractiveness, intentions to work for the organization and the fairness of the test higher than in their initial reactions. Ployhart, Ryan and Bennett 
(1999) report that fairness perceptions of cognitive and job knowledge tests increased with a positive selection outcome.

The issue we study is related to the more general theme of whether people's motivation is affected by the process by which an allocation is reached, in other words, whether information that is not about the outcome itself is pertinent for predicting subjects' behavior. We are, however, not aware of any experiment or model which specifically addresses whether, in a selection situation, the employee's behavior will depend on the procedures by which she has been chosen. We report on an experiment to study whether people's behavior is affected by the very fact that they are selected on the basis of information about their personal characteristics. Note that it would be difficult to carry out this type of analysis on the basis of field data alone, since in natural environments it would be unusual to find data with the desired variations in the selection procedure. In contrast, experiments make it possible to generate this kind of evidence in a systematic way.

We study a simple sequential selection situation and focus on two main hypotheses. The first is that selection on the basis of personal information will make the selected party more generous towards others. This is what we will refer to as the I-wantYOU effect. Our second hypothesis, which we will call the gratitude effect, posits that the selected party's increased generosity will favor more the selecting party than other parties involved. The first hypothesis refers to a possible change in the goodwill towards others in general, while the second refers to a change in the relative disposition towards two specific others. Note that the two potential effects are independent from each other. We also study the relevance of outside options and some aspects of the behavior of the selecting party. 


\section{EXPERIMENTAL DESIGN AND PROCEDURE.}

As part of our experimental design, we needed to generate information about participants' personal characteristics. To provide this kind of information, at the beginning of the experiment all participants were asked to fill out the '16 PApersonality questionaire'. This questionnaire was introduced by Brandstätter (1988) and serves as a German and reduced version of a more comprehensive self-rating of individual characteristics (see Cattel, Schneewind and Schroeder, 1983). We do not view this questionnaire necessarily as an appropriate tool for use in actual selection processes in natural settings. It is, however, a good way of obtaining some relevant personal information about subjects in our experimental setting. ${ }^{1}$

In the questionnaire subjects had to rate themselves on a scale from 1 to 9 , on 32 items related to 16 personality-related dimensions. When answering the questionnaire participants did not know about the actual decision task they would subsequently participate in. Subjects were then asked to make decisions in a three-person game in which they had the fixed role of party $\mathrm{X}, \mathrm{Y}$ or $\mathrm{Z} . \mathrm{X}$ is the party that makes the selection and $\mathrm{Y}$ and $\mathrm{Z}$ are the potential dictators or, as we will call them, allocators.

In the game, see figure 1, the three parties can share a total reward of 12 tokens in case that $\mathrm{X}$ gives up her outside option, $\mathrm{O}$, which yields q tokens for her and nothing for $\mathrm{Y}$ and $\mathrm{Z}$. In our experiments $\mathrm{q}$ will take on the values 3 and 6 . The allocator's distribution of $\mathrm{p}$ among the three parties can be described by the vector $(\mathrm{x}, \mathrm{y}, \mathrm{z})$ with $\mathrm{x}, \mathrm{y}, \mathrm{z}$ $\geq 0$ and $x+y+z=p$. For purely self-interested players the prediction of behavior in these games is very straightforward. If either $\mathrm{Y}$ or $\mathrm{Z}$ has been assigned dictatorial power, she will keep the entire pie, p, for herself regardless of how she has been selected. Anticipating this, a self-interested player $\mathrm{X}$ will always choose $\mathrm{O}$, since $\mathrm{q}$ is positive. 


\section{Insert Figure 1 about here}

Our main treatments differ only in what happens when $\mathrm{X}$ gives up her outside option. The selected allocator (hereafter, SA) treatment represents the selection situation discussed above: Party X can freely decide whether she gives up the outside option and whether she wants $\mathrm{Y}$ or $\mathrm{Z}$ to be the allocator. The SA treatment corresponds to the competitive environment we are mainly interested in. $\mathrm{X}$ can be seen as an employer or manager who has to hire one of the two employees or assign a task to one of them on the basis of available personal information about the candidates.

As a natural control for the SA treatment we conducted the random allocator (hereafter, RA) treatment in which, for the case that $\mathrm{X}$ gave up her outside option, the distributive power was randomly assigned to either $\mathrm{Y}$ and $\mathrm{Z}$, with a probability of $1 / 2$ each. Note that this procedure provides an unbiased benchmark at which personal characteristics can not influence the choice between $\mathrm{Y}$ and $\mathrm{Z}$.

Each session extended over three rounds; players' roles remain fixed over all three rounds. The only difference between rounds was that q was equal to 3 tokens in rounds 1 and 2 and equal to 6 tokens in round 3, which allows us to study the influence of variations in outside options. We used a round-robbin matching procedure and, hence, guaranteed that no participant was ever matched twice with the same partner in different rounds. In addition, subjects were not informed about the outcomes in rounds 1 and 2 until after the end of round 3. We decided to obtain more than one measurement from each subject to study differences between earlier and later play. We, however, used a procedure that avoided feedback effects so that changes in behavior over time can not be influenced by information of others' past behavior.

\footnotetext{
${ }^{1}$ An English translation of the personality questionnaire can be found in Appendix A.
} 
The answers to the personality questionnaire were used in both treatments. Player $\mathrm{X}$ could consult the answers of the two participants who had the $\mathrm{Y}$ and $\mathrm{Z}$ roles in her group, before choosing between $\mathrm{O}$ and $\mathrm{D}$ and, in the SA treatment, also between $\mathrm{D}_{\mathrm{Y}}$ and $\mathrm{D}_{\mathrm{Z}}$. She just had to enter into the computer the number corresponding to a certain question and instantly obtained the respective answers for the $\mathrm{Y}$ and $\mathrm{Z}$ players she was matched with. She was neither restricted in terms of time nor by the number of questions she was allowed to consult. The requests for information by $\mathrm{X}$ were recorded by the computer. This yields information about how much and which information X's decision for or against $\mathrm{O}$ and, in the SA treatment, for $\mathrm{Y}$ or for $\mathrm{Z}$, is based on. Only rather few items of the personality questionnaire were consulted by participants in the role of player X; we will come back to this fact in section 3.2.

In our experiments we followed the strategy elicitation method, i.e. we asked players $\mathrm{Y}$ and $\mathrm{Z}$ to decide in case they were selected. There is some empirical evidence that the form of play can make a difference (e.g., Schotter, Weigelt and Wilson, 1994). While there is no consensus on why this is so, a possible explanation is that spontaneous play tends to evoke a hot, or more emotional, response, while the conditional form of play used here tends to evoke a cold, or more studied, response. In our context, conditional play might diminish the impact of the selection procedure, thereby dampening down some of our treatment effects. ${ }^{2}$

The experiment was performed in the computer laboratory of the economics faculty of Humboldt-University in Berlin. ${ }^{3}$ The software was written with the help of the z-tree software package (Fischbacher, 1999). We conducted two sessions for each of the treatments. Each session had 15 participants who were randomly assigned to one of the

\footnotetext{
${ }^{2}$ Brandts and Charness (2000) find little evidence for this conjecture in the context of two-player sequential prisoner's dilemma and chicken games, using a no-feedback design.

${ }^{3}$ Appendix B contains a translation of the instructions.
} 
three roles $\mathrm{X}, \mathrm{Y}$ and $\mathrm{Z}$. We, therefore, had a total of 2 (treatments)x 2 (sessions)X 15 (participants per session=60 participants. ${ }^{4}$ This means that we had observations for 10 subjects in each of $\mathrm{X}, \mathrm{Y}$ and $\mathrm{Z}$ roles in each of the treatments. Due to the use of the strategy method we could pool the observations of 20 subjects in either $\mathrm{Y}$ or $\mathrm{Z}$ role and analyze them together as second mover data.

\section{RESULTS.}

The data file of each participant in the $\mathrm{X}$ role consists of her answers to the personality questionnaire and, for each of the three rounds, of her information requests about $\mathrm{Y}$ and Z's answers to the questionnaire and her decisions in the game. For participants in the role of $\mathrm{Y}$ or $\mathrm{Z}$ the data only include the first and third of the above three items. Although participants decide repeatedly, when comparing behavior in the same round each individual decision was treated as an independent observation, since no feedback on others' behavior was provided between rounds. Thus the only statistical drawback arises when we pool the data from different rounds, e.g. from rounds 1 and 2 with $\mathrm{q}=3$, for the same subject.

We will start with the analysis of behavior of subjects in the $\mathrm{Y}$ and $\mathrm{Z}$ roles. Since they are the second movers in the game, their decisions can not be influenced by strategic considerations and will depend exclusively on motivational factors. To complete the picture we then study some features of X's behavior,

\subsection{The behavior of second movers ( $Y$ and $Z)$.}

Table 1 presents descriptive statistics of how the $\mathrm{Y}$ and $\mathrm{Z}$ players - in the table

\footnotetext{
${ }^{4}$ The minimum, average and maximum payoff were 10, 18.6 and $34 \mathrm{DM}$, including a show-up fee of 10 DM. 1 DM equals .5 Euro. A typical session needed around 45 minutes, 10 minutes for filling out the
} 


\section{Insert Table 1 about here}

referred to as allocators - distribute the 12 units of the pie between the three participants. The decisions of $\mathrm{Y}$ and $\mathrm{Z}$ are pooled, since these two roles are ex ante identical. The data shown in table 1 correspond to all the information we have about the behavior of $\mathrm{Y}$ and $\mathrm{Z}$, i.e. it includes the decisions of both those allocators that were actually chosen and those who were avoided. Table 1, hence reflects Y's and Z's behavior without conditioning on first players' behavior. In section 3.2 below we will show related information for which the $\mathrm{X}$ players' behavior will be taken into account. Note, in passing, the confirmation in both treatments of the well-known result that subjects give away considerable amounts in situations in which a player has all the distributive power.

We first want to focus on evidence pertaining to the I-want-YOU effect, i.e. on the effect of the treatment on the share kept by the allocator. The evidence in table 1 leads to our first regularity.

\section{Regularity 1:}

In round 1, knowingly selected allocators keep less for themselves than randomly chosen ones.

In a descriptive sense, regularity 1 holds for all three rounds, since the mean demands by allocators in rounds 1,2 and 3 are $8.65,9.85$ and 9.35 for RA and only $6.75,8.45$ and 8.95 for SA. However, using a Mann-Whitney U-test, it is significant in round 1, with a $\mathrm{p}$-value of $\mathrm{p}=0.040$, and not in rounds 2 and 3 . If, in spite of the repeated measurement issue, one pools the data from rounds 1 and 2, involving the same outside option, the pvalue is $\mathrm{p}=0.027$.

standard personal questionaire, 10 minutes for reading the instructions and privately answering clarifying 
Recall that we use a no-feedback design so that the difference between rounds can not be explained by learning from past outcomes. One possible interpretation of the absence of a statistically significant effect in rounds 2 and 3 is that round 1 behavior corresponds to a hot or more emotional reaction while behavior in rounds 2 and 3 is colder or more studied and reflects what people do on second thoughts. ${ }^{5}$ If this interpretation is correct then one can conceive of the effect we find for round 1 as the expression of some additional goodwill which will only be present in the initial stages of the relation that starts with the selection process.

The data shown in table 2 give some additional information about second mover

\section{Insert Table 2 about here}

behavior. The third and fourth column shows the number \# of players that kept more than half the pie and kept half the pie or less, respectively. In the fifth to ninth column the results of binomial tests are displayed that show whether a proportion $P$ of participants that keep an amount smaller or equal to 6 lies below the given percentage. The cells with no entries correspond to cases where the actual proportion is already larger than posited by the corresponding hypothesis.

A first result here is that in all three rounds of both treatments the proportion of subjects is always larger than $10 \%$, the largest $\mathrm{p}$-value being $\mathrm{p}=0.043$. Additionally, in all three rounds of the SA-treatment, the proportion is significantly larger than $20 \%$ with p-values less than 5 percent, but not so in the RA-treatment. Here the proportion is only significantly higher the $20 \%$ in round 1 , with a $p$-value of $p=0.087$. The result we wish to highlight is that for the first round of SA we can reject the hypothesis that the proportion of subjects that keep 6 or less is smaller than $40 \%(\mathrm{p}=0.021)$, while for RA in round 1 the actual proportion is already smaller than $40 \%$.

questions and about 10 minutes, 7 minutes, 7 minutes for the $1^{\text {st }}, 2^{\text {nd }}$ and $3^{\text {rd }}$ round. 
The next regularity summarizes the information from table 2 that we wish to highlight:

\section{Regularity 2:}

In round 1 of the selected allocator treatment (SA) the proportion of subjects who keep 6 or less is significantly larger than $40 \%$ while for round 1 of RA the hypothesis that the proportion is less than $20 \%$ cannot be rejected.

Taken together regularities 1 and 2 are our evidence in favor of the I-want-YOU effect. The question now is whether we can go, in a sense, one step further and find evidence for the gratitude effect.

Table 3 shows by treatment and round, the number of cases in which $\mathrm{X}$

\section{Insert Table 3 about here}

obtained more, the same or less than the third party. It also shows the results of a twotailed Wilcoxon Signed-Rank Test which tests the null hypothesis of no difference against the "gratitude hypothesis" that X receives more than the third party. As can be seen in round 1 the effect is significant at the 5\% level for SA but not significant for RA in any of the three rounds.

\section{Regularity 3:}

In round 1 of the selected allocator treatment (SA) the allocator gives more to $X$ than to the remaining player.

We can at this point summarize and comment on the validity of our main hypotheses. The data are consistent with the I-want-YOU and gratitude effects in first reactions (round 1).

\footnotetext{
${ }^{5}$ One can also think of the fading away of the I-want-YOU effect in terms of some kind of satiation.
} 
Our final observation concerning second mover behavior is about the influence of X's outside option on allocator's behavior. On the basis of the data in table 1 we can state the following.

\section{Regularity 4:}

The outside option has no effect since:

1. X players receive less than the outside option,

2. Its size (3 or 6) has no effect on the distribution of the pie.

At first sight, regularity 4 may seem surprising since, as mentioned above, second movers have been found to make their choices among outcomes available to them dependent on the alternatives available to first movers (see, for instance, Brandts and Solà (2001) and Charness and Rabin (forthcoming)). Nevertheless, our result may be rationalized in the following way. In our game both outside options are very unfair, since they give $100 \%$ of the smaller pie to the $\mathrm{X}$ player. (In comparison, actual mean behavior in our round 2 gives shares of $17.1 \%, 70.4 \%$ and $12.5 \%$ to the three players.) Therefore, in both cases, player X's giving up of her outside option is rather seen as a duty than as an act of generosity and, hence, does not affect the allocator's subsequent behavior. This possibility is unaffected by the change in X's outside option. ${ }^{6}$

\subsection{First mover behavior.}

First mover behavior is influenced by both strategic and motivational considerations which can not be easily disentangled. In addition we have fewer data - 10 independent decisions per treatment - for first than for second movers. The information that we

\footnotetext{
${ }^{6}$ In a related game, the lost wallet game, Dufwenberg and Gneezy (2000) also find that the size of the outside option does not affect allocators' behavior.
} 
present in this section should, hence, just be seen as a descriptive complement to the results presented earlier.

\section{Insert Table 4 about here}

Table 4 gives some insight into the interplay between the decisions of $\mathrm{X}$ and of those of the allocators. It shows descriptive statistics for the amounts allocated by the allocator to the three players involved, distinguishing between actually chosen, c, and avoided, a. ${ }^{7}$ The information contained in this table has a somewhat different character than the one shown in table 1. Although these data still show cold conditional responses given by second players, they correspond to that subset of conditional responses which player $\mathrm{X}$ has, through her choice, made relevant for payoff determination.

The feature of this table which we want to highlight at this point is that in round 3 the X players, in both the SA and the RA treatment, obtain, from chosen allocators, more than half the total pie. This remark is, however, based on very few observations, so that we only can say that we have a hint that, both in SA and RA, X players learn to select allocators who favor them.

\section{Insert Table 5 about here}

Table 5 gives information per round and per treatment of those items in the questionnaire which at least in one of the treatments were among the top ten of consulted items. ${ }^{8}$ Item 23 asks for (in)dependence, 4 for (not) being headstrong, 3 for (not) trusting, 24 for (not) being cool, 2 for whether one is slow or quick in thinking, 18 for (no) willingness to experiment and 7 for (not) trying to be independent. ${ }^{9}$ One can say that X participants have frequently tried to find out more about the potential allocators

\footnotetext{
${ }^{7}$ Since in the RA-treatment the selection by $\mathrm{X}$ is purely hypothetical we stated the amounts of both players, $\mathrm{Y}$ and $\mathrm{Z}$, as chosen when $\mathrm{X}$ decided to distribute the pie.

${ }^{8}$ Whenever a $X$ player consulted an item in the questionnaire, she obtained the information corresponding to both the $\mathrm{Y}$ and the $\mathrm{Z}$ player she was paired with.
} 
where the most frequently retrieved items are related to trustworthiness, analytical talents and social independence. ${ }^{10}$

\section{SUMMARY AND CONCLUSIONS.}

We have experimentally studied interdependent motivation in a three-person situation in which a player may assign power over the distribution of a pie to one of two other players. Our main findings are what we have called the I-want-YOU and gratitude effects. The results show that selection may have purely psychological effects, which, in our case, are not negative in any sense. Other stylized facts of this kind may continue to arise and call for more encompassing types of models.

We feel that the effects we find are potentially important phenomena since selection situations are quite pervasive, specially in the labor market and in organizations, but also in more personal matters like the selection of a marriage partner. The type of regularities we observe may be interpreted as reflecting considerable emotional involvement of subjects. A selection situation is probably a highly interpersonal affair. In his discussion of selection as a social process, Herriott (1989, p.171) states: "Selection is not the gate through which applicants must pass before they can relate to the organization; it is itself part of the relationship".

Recall that our results are obtained with the cold strategy method in an experimental lab. Behavior in an experiment with the (moderately) hot direct-response method, or even in a naturally ocurring situation should not be expected to produce smaller I-want-YOU and gratitude effects than the ones we have reported on here.

\footnotetext{
${ }^{9}$ For the meaning of the other most frequently consulted items, please go to appendix A.

${ }^{10}$ A statistical test rejects the null hypothesis of $\mathrm{X}$ being equally interested in all questions in favor of the alternative of concentration on a subset of questions.
} 


\section{REFERENCES}

Bauer T., C. Maertz, M. Dolen and M. Campion (1998), "Longitudinal assessment of applicant reactions to employment testing and test outcome feedback", Journal of Applied Psychology, 83, 892-903.

Berg, J., J. Dickhaut and K. McCabe (1995), “Trust, Reciprocity and Social History”, Games and Economic Behavior, 10, 1, 122-142.

Brandstätter, H. (1988), "Sechzehn Persönlichkeits-Adjektivskalen (16PA) als Forschungsinstrument anstelle de 16PF" (Sixteen Personality Adjective Scales as a substitute for the 16PF in research settings), Zeitschrift für experimentelle und angewandte Psychologie, 35, 370-391.

Brandts, J. and G. Charness (2000), "Hot vs. Cold: Sequential Responses in Simple Experimental Games", Experimental Economics, 2, 227-238.

Brandts, J. and C. Solà (2001), "Reference Points and Negative Reciprocity in Simple Sequential Games", Games and Economic Behavior, 36, 138-157.

Cattel, R. B., K. A. Schneewind and G. Schroeder (1983), ,"Der 16-Persönlichkeits-Faktoren Test" 16 PF [The 16-Personality-Factor-Test.16PF], Bern: Huber.

Charness, G. and M. Rabin (forthcoming), “Understanding Social Preferences with Simple Tests", Quarterly Journal of Economics.

Dufwenberg, M. and U. Gneezy (2000), "Measuring Beliefs in an Experimental Lost Wallet Game”, Games and Economic Behavior, 30, 163-182.

Fehr, E., G. Kirchsteiger and A. Riedl (1993), "Does Fairness Prevent Market Clearing? An Experimental Investigation”, Quarterly Journal of Economics, 108, 2, 437-460.

Fischbacher, U. (1999), "z-Tree. Zurich Toolbox für Readymade Economic Experiments”, University of Zurich.

Gilliland, S. (1993), “The Perceived Fairness of Selection Systems: An Organizational Justice Perspective", Academy of Management Review, 18, 4, 694-734.

Hannan, R., J. Kagel and D. Moser (forthcoming), "Partial Gift Exchange in Experimental Labor Markets: Impact of Subject Population Differences, Productivity Differences and Effort Request on Behavior", Journal of Labor Economics.

Herriott, P. (1989), "Selection as a Social Process" in Advances in Selection and Assessment, (M. Smith and I. Robertson, eds.), John Wiley \& Sons Ltd., London, 171-187.

Hough, L. and F. Oswald (2000), "Personnel Selection: Looking Toward the Future - Remembering the Past”, Annual Review of Psychology, 51, 631-664.

Ployhart, R., A. Ryan and M. Bennett (1999), “Explanations for selection decisions: applicants' reactions to informational and sensitivity features of explanations", Journal of Applied Psychology. In press.

Schotter, A., K. Weigelt, and C. Wilson, “A Laboratory Investigation of Multiperson Rationality and Presentation Effects," 1994, Games and Economic Behavior, 6, 445-468. 
Table 1: Amounts Assigned by Allocators to X, Herself and the Remaining Player

\begin{tabular}{|c|c|c|c|c|c|c|c|}
\hline \multicolumn{2}{|c|}{ Treatments } & \multicolumn{3}{c|}{ RA } & \multicolumn{3}{c|}{ SA } \\
\hline \multirow{2}{*}{ Round } & $\begin{array}{c}\text { Shares } \\
\text { Of the pie p }\end{array}$ & $\mathbf{X}$ & Allocator & $\mathbf{3}^{\text {rd }}$ player & $\mathbf{X}$ & Allocator & $\mathbf{3}^{\text {rd }}$ player \\
\hline \multirow{4}{*}{$\mathbf{1}$} & Mean & 1.95 & 8.65 & 1.4 & 3.3 & 6.75 & 1.95 \\
\cline { 2 - 9 } & Mode & 0 & 12 & 0 & 0 & 4 & 0 \\
\cline { 2 - 9 } & S.d. & 1.76 & 2.88 & 1.56 & 2.92 & 3.6 & 1.73 \\
\cline { 2 - 9 } & Min & 0 & 4 & 0 & 0 & 0 & 0 \\
\cline { 2 - 9 } & Max & 4 & 12 & 4 & 12 & 12 & 4 \\
\hline \multirow{4}{*}{2} & Mean & 1.35 & 9.85 & .8 & 2.05 & 8.45 & 1.5 \\
\cline { 2 - 9 } & Mode & 0 & 12 & 0 & 0 & 12 & 0 \\
\cline { 2 - 9 } & S.d. & 2.21 & 3.08 & 1.4 & 2.23 & 3.59 & 1.7 \\
\cline { 2 - 9 } & Min & 0 & 4 & 0 & 0 & 4 & 0 \\
\cline { 2 - 9 } & Max & 7 & 12 & 4 & 6 & 12 & 4 \\
\hline \multirow{4}{*}{3} & Mean & 1.95 & 9.35 & .7 & 1.95 & 8.95 & 1.1 \\
\cline { 2 - 9 } & Mode & 0 & 12 & 0 & 0 & 12 & 0 \\
\cline { 2 - 9 } & S.d. & 3.35 & 3.75 & 1.334 & 2.81 & 3.73 & 1.77 \\
\cline { 2 - 8 } & Min & 0 & 0 & 0 & 0 & 3 & 0 \\
\cline { 2 - 9 } & Max & 12 & 12 & 4 & 8 & 12 & 6 \\
\hline
\end{tabular}

Table 2: Results of Binomial Tests for the Proportion of Allocators that keep half the pie or less

\begin{tabular}{|c|c|c|c|c|c|c|c|c|}
\hline Treatment & Round & \# $>$ 6 & \# $\leq \mathbf{6}$ & $\begin{array}{r}\mathbf{P} \leq \\
\mathbf{1 0 \%}\end{array}$ & $\begin{array}{r}\mathbf{P} \leq \\
\mathbf{2 0 \%}\end{array}$ & $\begin{array}{r}\mathbf{P} \leq \\
\mathbf{3 0 \%}\end{array}$ & $\begin{array}{r}\mathbf{P} \leq \\
\mathbf{4 0 \%}\end{array}$ & $\begin{array}{c}\mathbf{P} \leq \\
\mathbf{5 0 \%}\end{array}$ \\
\hline \multirow{4}{*}{ SA } & $\mathbf{1}$ & 7 & 13 & .000 & .000 & .001 & .021 & .134 \\
\cline { 2 - 10 } & $\mathbf{2}$ & 11 & 9 & .000 & .010 & .113 & .404 & - \\
\hline \multirow{3}{*}{$\mathbf{3}$} & $\mathbf{3}$ & 12 & 8 & .000 & .032 & .228 & - & - \\
\cline { 2 - 10 } & $\mathbf{2}$ & 15 & 7 & .002 & .087 & .392 & - & - \\
\cline { 2 - 10 } & $\mathbf{3}$ & 15 & 5 & .043 & .370 & - & - & - \\
\hline
\end{tabular}


Table 3: Comparison between the shares of $X$ and the Third Player

\begin{tabular}{|c|c|c|c|c|c|c|c|}
\hline & Round & $\mathbf{X}$ mean & $\begin{array}{c}\mathbf{3}^{\text {rd }} \\
\text { player } \\
\text { mean }\end{array}$ & $\begin{array}{c}\# \\
\mathbf{3}^{\text {rd }}<\mathbf{X}\end{array}$ & $\begin{array}{c}\# \\
3^{\text {rd }}>\mathbf{X}\end{array}$ & $\begin{array}{c}\# \\
3^{\text {rd }}=\mathbf{X}\end{array}$ & $\begin{array}{c}\mathbf{2 - t a i l e d} \\
\text { test }\end{array}$ \\
\hline \multirow{3}{*}{ SA } & $\mathbf{1}$ & 3.3 & 1.95 & 6 & 2 & 12 & .049 \\
\cline { 2 - 9 } & $\mathbf{2}$ & 2.05 & 1.5 & 4 & 1 & 15 & .176 \\
\cline { 2 - 9 } & $\mathbf{3}$ & 1.95 & 1.1 & 5 & 1 & 14 & .172 \\
\hline \multirow{3}{*}{ RA } & $\mathbf{1}$ & 1.95 & 1.4 & 5 & 2 & 13 & .149 \\
\cline { 2 - 9 } & $\mathbf{2}$ & 1.35 & .8 & 2 & 1 & 17 & .285 \\
\cline { 2 - 8 } & $\mathbf{3}$ & 1.95 & .7 & 4 & 1 & 15 & .138 \\
\hline
\end{tabular}

Table 4: Comparison of the Amounts Allocated by Chosen and Avoided Allocators.

\begin{tabular}{|c|c|c|c|c|c|c|c|c|c|c|c|c|c|}
\hline \multirow[t]{2}{*}{ Round } & \multirow[t]{2}{*}{ Statistic } & \multicolumn{2}{|c|}{ SA/X } & \multicolumn{2}{|c|}{ SA/alloc. } & \multicolumn{2}{|c|}{$S A / 3^{\text {rd }}$} & \multicolumn{2}{|c|}{$\mathbf{R A} / \mathbf{X}$} & \multicolumn{2}{|c|}{ RA/alloc. } & \multicolumn{2}{|c|}{$R A / 3^{\text {rd }}$} \\
\hline & & C & $A$ & C & $a$ & C & $a$ & C & $a$ & C & $a$ & C & $a$ \\
\hline \multirow{6}{*}{1} & $\mathrm{~N}$ & 7 & 13 & 7 & 13 & 7 & 13 & 16 & 4 & 16 & 4 & 16 & 4 \\
\hline & Mean & 2 & 4 & 8 & 6,08 & 2 & 1,92 & 1,88 & 2,25 & 8,69 & 8,5 & 1,43 & 1,25 \\
\hline & Mode & 3 & 4 & 12 & 4 & 0 & 0 & 0 & 4 & 12 & 4 & 0 & 0 \\
\hline & s.d. & 1,63 & 3,27 & 3,12 & 3,68 & 1,73 & 1,8 & 1,75 & 2,06 & 2,87 & 3,42 & 1,55 & 1,89 \\
\hline & Min & 0 & 0 & 4 & 0 & 0 & 0 & 0 & 0 & 5 & 4 & 0 & 0 \\
\hline & Max & 4 & 12 & 12 & 12 & 4 & 4 & 4 & 4 & 12 & 12 & 4 & 4 \\
\hline \multirow{6}{*}{2} & $\mathrm{~N}$ & 7 & 13 & 7 & 13 & 7 & 13 & 8 & 12 & 8 & 12 & 8 & 12 \\
\hline & Mean & 3,14 & 1,46 & 6,86 & 9,31 & 2 & 1,23 & 1,25 & 1,41 & 9,5 & 10,1 & 1,25 & 0,5 \\
\hline & Mode & 4 & 0 & 4 & 12 & 0 & 0 & 0 & 0 & 12 & 12 & 0 & 0 \\
\hline & s.d. & 2,26 & 2,07 & 3,63 & 3,4 & 2 & 1,54 & 1,75 & 2,54 & 3,51 & 2,91 & 1,75 & 1,17 \\
\hline & Min & 0 & 0 & 4 & 4 & 0 & 0 & 0 & 0 & 4 & 5 & 0 & 0 \\
\hline & Max & 6 & 6 & 12 & 12 & 4 & 4 & 4 & 7 & 12 & 12 & 4 & 3 \\
\hline \multirow{6}{*}{3} & $\bar{N}$ & 2 & 18 & 2 & 18 & 2 & 18 & 2 & 18 & 2 & 18 & 2 & 18 \\
\hline & Mean & 7 & 1,39 & 3,5 & 9,56 & 3,5 & 0,5 & 7 & 1,39 & 5 & 9,83 & 0 & 0,78 \\
\hline & Mode & 6 & 0 & 3 & 12 & 3 & 0 & 6 & 0 & 4 & 12 & 0 & 0 \\
\hline & s.d. & 1,41 & 2,33 & 0,7 & 3,42 & 0,58 & 1,37 & 1,41 & 3,01 & 1,41 & 3,63 & 0 & 1,4 \\
\hline & Min & 6 & 0 & 3 & 3 & 3 & 0 & 6 & 0 & 4 & 0 & 0 & 0 \\
\hline & Max & 8 & 7 & 4 & 12 & 4 & 4 & 8 & 12 & 6 & 12 & 0 & 4 \\
\hline
\end{tabular}


Table 5: Most Frequently Consulted Items in the Personality Questionnaire

\begin{tabular}{|c|c|c|c|c|c|c|c|}
\hline \multicolumn{2}{|c|}{ Treatment } & \multicolumn{3}{c|}{ RA } & \multicolumn{3}{c|}{ SA } \\
\hline \multicolumn{2}{|c|}{ Round } & 1 & 2 & 3 & 1 & 2 & 3 \\
\hline $\begin{array}{c}\text { Question } \\
\text { number }\end{array}$ & $\begin{array}{c}\text { Total number of } \\
\text { requests }\end{array}$ & 65 & 69 & 50 & 74 & 81 & 45 \\
\hline 23 & 40 & 6 & 5 & 4 & 5 & 5 & 4 \\
\hline 4 & 38 & 3 & 4 & 3 & 4 & 6 & 2 \\
\hline 9 & 38 & 2 & 6 & 4 & 6 & 6 & 2 \\
\hline 24 & 35 & 4 & 5 & 2 & 5 & 4 & 2 \\
\hline 2 & 33 & 3 & 3 & 2 & 6 & 6 & 1 \\
\hline 18 & 32 & 5 & 6 & 2 & 3 & 5 & 1 \\
\hline 11 & 28 & 2 & 3 & 2 & 6 & 3 & 2 \\
\hline 7 & 25 & 4 & 2 & 3 & 3 & 2 & 2 \\
\hline 19 & 25 & 5 & 2 & 0 & 4 & 2 & 2 \\
\hline 10 & 22 & 2 & 2 & 1 & 0 & 4 & 3 \\
\hline 32 & 20 & 1 & 2 & 2 & 3 & 3 & 3 \\
\hline 25 & 19 & 1 & 4 & 2 & 1 & 2 & 1 \\
\hline 6 & 19 & 3 & 2 & 0 & 1 & 2 & 1 \\
\hline 3 & 16 & 2 & 2 & 4 & 1 & 0 & 2 \\
\hline
\end{tabular}

Figure 1: Experimental Design

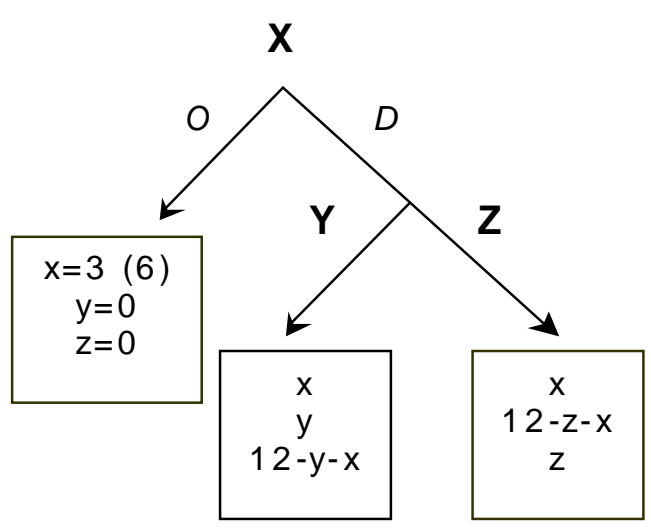


Appendix A: Translated Questionnaire.

In what follows you will find a list of personal qualities. Please describe yourself using this list by indicating in each row by means of a cross to what extent either the left or the right quality applies to you. Even if in some cases you would like to say, that depending on the circunstances both qualities apply or that the qualities do not constitute contradictions, you should only choose one of the values between 1 and 9 and, thereby, indicate which of the two qualities is more accurate. Since all responses are anonymous you can indicate without worrying what you really think of yourself. There is nobody on who you need to make a good impression. Only if you answer very honestly can the results be used.

1. Matter-of-fact

2. Slow thinker

3. Easy to upset

4. Ready to adapt

5. Quiet

6. Careless

7. Timid

8. Thick-skinned

9. Trusting

10. Realistic

11. Direct

12. Self-satisfied

13. Holding on to the usual

14. Needing support

15. Lacking self-control

16. Balance

17. Tense

18. Happy to experiment

19. Trained in reflection

20. Sensitive

21. Anxious

22. Full of fantasy

23. Self-assertive

24. Warm-hearted

25. Firm-principled

26. Critical

27. Likes to be independent

28. Cultivated

29. Self-controlled

30. Self-assured

31. Emotionally resistant

32. Hungry for experiences
O OOOOOOO

O O OOOOOO

O OOOOOOOO

O OOOOOOO

O O O OOOOO

O O OOOOOO

O O O O O OO

O O OOOOOO

O O O O O OO

O O O OOOOO

O OOOOOOOO

O OOOOOOOO

O O O O O OO

O O O O OOOO

O O O OOOOO

O OOOOOOOO

O OOOOOOO

O O O OOOOO

O OOOOOOOO

O OOOOOOOO

O O O OOOOO

O O O OOOOO

O O O O O O O

O O O OOOOO

O O OOOOOO

O O O OOOOO

O O O OOOOO

O O O O OOOO

O OOOOOOOO

O OOOOOOOO

O O O O O OO

O O O OOOOO
Outgoing

Quick thinker

Emotionally stable

Headstrong

Lively

Conscientious

Daring

Sensitive

Distrustful

Dreamy

Diplomatic

Self-doubting

Open to changes

Self-reliant

Disciplined

Irritable

Cool

Oriented to what has been tried and tested

Untrained in reflection

Tough

Carefree

Down-to-earth

Ready to subordinate

Cold

Easygoing

Lenient

Likes to be with others

Natural

Changeable

Shy

Emotionally fragile

Needing quietness 


\section{Appendix B: Instructions.}

Welcome and thank you very much for your disposition to participate in this experiment. Any contact to other participants in this room is from on not allowed any more. If you have questions, raise your hand and we will come to your seat.

First please fill out a questionnaire (see also the sample questionnaire). Please answer the questions from your personal perspective, by clicking on the scale to what degree the left or the right quality applies to you. Please answer all questions seriously. You answers to the questionnaires as well as during the subsequent experiments will of course be treated anonymously. This means, nobody will learn about your identity just as you will not learn anything about the identity of the other participants.

You will receive more instructions after having filled out the questionnaire.

Thank you very much for filling out the questionnaires. The actual experiment starts now. Please continue to be quiet and avoid any communication with the other participants. If you have questions, please raise your hand.

The instructions for this experiment are identical for all participants.

The experiment consists of three rounds. In each round 3 participants interact with each other who will be called $\mathrm{X}, \mathrm{Y}$ and $\mathrm{Z}$. Whether you act as $\mathrm{X}, \mathrm{Y}$ or $\mathrm{Z}$ will be randomly determined at the beginning of the experiment and communicated to you. Your role will be unchanged throughout the experiment. In each round two new participants will be randomly assigned to you. You will, however, not meet any oparticipant more than once.

The first two rounds develop according to the following pattern.

A money amount of $12.00 \mathrm{DM}$ kann be divided between $\mathrm{X}, \mathrm{Y}$ and $\mathrm{Z}$. Whether it gets to a division of the total amount, is initially decided by participant $\mathrm{X}$. Prior to her decisions $\mathrm{X}$ can ask for and consult answers given by $\mathrm{Y}$ and $\mathrm{Z}$ to the questions. ${ }^{11}$ Naturally the anonymity of the different participants is kept. $\mathrm{X}$ knows only that the responses come from a $\mathrm{Y}$ or $\mathrm{X}$ assigned to him.

Then $\mathrm{X}$ can choose between two variants:

Variant 1: The total money amount of 12:00 DM is not split. Participant $X$ receives an amount of $\mathrm{x}=3.00 \mathrm{DM}$. Participants $\mathrm{Y}$ and $\mathrm{Z}$ receive nothing.

\footnotetext{
${ }^{11}$ To do this $\mathrm{X}$ just has to enter into the computer the numbers corresponding to the quality-pairs that he is interested in. (For the corresponding numbers see the sample questionnaire).
} 
Variant 2: The total money amount of 12:00 DM is split. In this case participant $\mathrm{Y}$ or participant $\mathrm{Z}$ decides what part of the total amount the three participants (X, Y and Z) receive. Whether Y Or Z decides about the split-up is determined by participant X. (Whether X or Y decides about the split-up will be determined randomly (with equal chance)).

This means: $\mathrm{X}$ decides between Variant 1 and Variant 2. In case he chooses Variant $2 \mathrm{X}$ decides also whether $\mathrm{Y}$ or $\mathrm{Z}$ determines the split-up of the total amount. Participants $\mathrm{Y}$ and $\mathrm{Z}$ make their proposal for the split-up of the total amount without knowledge of the choice of $\mathrm{X}$. Their decisions become effective if $\mathrm{X}$ chooses Variant 2 and the corresponding participant ( $\mathrm{Y}$ or $\mathrm{Z}$ ) is determined by $\mathrm{X}$ for the split-up of the total amount.

Round 3 develops according to a similar pattern. The only difference with the preceding rounds is that in case of choosing Variant $1 \mathrm{X}$ obtains a money amount of $\mathrm{x}=6.00 \mathrm{DM}$.

Please note that at the beginning of each round you will be assigned two new participants such that you never interact more than once with one of the assigned participants.

At the end of the experiment (after decisions for all 3 rounds will have been made) all participants will be informed for the different rounds about

- what Variant was chosen by X,

- $\quad$ in case Variant 2 was chosen, whose decision became effective (the one of $\mathrm{Y}$ or the one of Z),

- $\quad$ what payoff the participant earned in the different rounds and what total payoff resulted from that.

In addition to the payoff you obtain in the rounds, you will receive a participation fee of $10.00 \mathrm{DM}$, which will be part of your total payoff. 